\title{
Editorial
}

\section{Open Access and Science Communication. Reflections on the need for a more open communication environment}

\begin{abstract}
While several scientific communities have discussed the emergence of Open Access publishing in depth, in the science communication community this debate has never been central. Scholars in most scientific disciplines have at their disposal Open Access options such as journals, repositories, preprint archives and the like. Ironically enough, a community devoted to the study of science's communication structures is witnessing this transformation without being directly involved. Both structural and cultural obstacles hamper the growth of an Open Access sector in science communication publishing. With this editorial I hope to start a debate on the need for a more open communication environment in our academic practice.
\end{abstract}

I know it might sound incredible for a community whose main focus is public communication, but, at least in my perspective, one of the main results of the Public Communication of Science and Technology Conference was the fact that we realised how badly our community needs to communicate outside its own boundaries. Ironically enough, this is exactly the lesson we have been trying to teach scientists for decades. Should we turn to ourselves in an exercise of self-reflection? In this short editorial I try to suggest why we should take into account the need to embrace different communication practices, and I hope to start a debate on the need for a more open communication environment in our academic practice.

Last April, hundreds of researchers, teachers, journalists and other practitioners met in Florence for the twelfth PCST World Conference. Among the many topics that were tackled during the conference, on a few occasions the problem of the communicative structure of our community surfaced, and I believe that a few round tables and plenary assemblies showed that we need to update and strengthen our reflection on the way PCST scholars communicate in public. As we all are aware, history and sociology of science have taught us that the communicative tools and practices researchers adopt depend on the incentive system that sustains the research community itself. Thus, for the least academic part of the PCST community, and I am referring to people and groups working, for example, on museum studies, journalism and education, public communication is the main way to diffuse ideas and knowledge. For these people, daily, public interactions in the open are commonplace and an awareness about the need to address different publics are reflected in their every day practices. Here, I do not want to mention the dozens of examples of how vital, open and interactive the science communication community can be: you know most of them.

The problem comes from those parts of the PCST community who have stronger links with academia. I believe we have not incorporated into our daily and academic practices the very suggestions, critiques and changes we have been proposing to the scientific community for decades. We study public communication, but our public communication practices are far from being up-to-date. Even though the academic world might seem to work on different, more internal incentives, we all know public communication to be a vital prerequisite for the growth, expansion and acceptance of a scientific field. Furthermore, we are aware that - I know it is pointless to repeat this - knowledge production is a communicative enterprise and public communication is the site where new knowledge is debated, negotiated, produced. Rich knowledge often emerges from rich communication practices.

While we could discuss the many ways to disseminate our work and transform it into a matter of public discussion among scientists, politicians, funders, and citizens, here I focus on one specific issue: access to science communication scholarly publishing. The Journal of Science Communication is probably the only Open Access journal specifically devoted to science communication scholarship. The overwhelming majority of academic works around science communication are published in traditional journals that have no Open Access policies and, thus, run the risk of not being accessible to developing countries 
colleagues, policy makers and science journalists, not to mention other practitioners and lay citizens. It might sound odd, but while several scientific communities have discussed in depth the need and the problems behind Open Access publishing, in the PCST community this debate has never been central. Scholars in most scientific disciplines now use OA options, such as journals, repositories, preprint archives and the like. Ironically enough, a community devoted to the study of science's communication structures is witnessing this transformation without being directly involved. Science communication scholarship is seldom published in Open Access journals.

Another facet of the problem is that most journals (JCOM included) do not adopt up-to-date tools for social media dissemination and discussion. While several online scientific journals are starting to provide their readership with tools that allow open discussion of the content they publish, most reference journals for the PCST community are closed and somehow "old fashioned". I am not merely talking about blogs here. The journals in which we publish do not recognise new ways of assessing content relevance, such as social network's impact, number of downloads, comments, and so on. Science communication scholarship seldom reverberates through social media.

What is to be done then? Obviously, we must recognise that these problems are important for the social sciences in general. But science communication has its own peculiarities. On the one hand, there is a structural problem. Open Access publishing can be costly, both financially and from the viewpoint of the energy needed to launch a new journal or start a new archive. Academic science communication suffers from chronic lack of funding and has not established itself as an institutionalised discipline, which make things more difficult. But a cultural problem is at play as well. As long as a new generation of science communication researchers does not question the current system, things won't change. Finally, it is not clear whether we can rely on current corporate academic publishers for a future shift towards a more open communication environment. Even though they have recently started OA experiments, academic publishers such as Sage or Elsevier are private companies whose business model is based on subscriptions by university libraries and they do not have any incentive to open up their content to a broader readership. It is likely that, exactly as in most scientific fields, change will be based on external pressure, rather than on publishers' own decisions. Independent action is the prerequisite for a change.

As I mentioned, the history of science's communication systems is linked to the economic and social incentives that sustain different communication practices. But we also know that technical innovations have transformed these practices by giving scientific communities new tools that can be used in a more independent and open fashion. The advent of printing is one of the main factors that was behind the scientific revolution and the shift towards the establishment of open science. The technological innovation represented by print brought with it the emergence of new publics for science and gave scientists the opportunity to put an independent and open system for scholarly publishing into place. Yet according to some authors, that very system is now hampering the emergence of new and more open practices. On the other hand, the Internet is giving us new tools and science itself is providing us with examples and teaching us lessons about the feasability and desirability of Open Access publishing: why don't we start an (open) debate on our publishing system?

Alessandro Delfanti

How TO CITE: $\quad$ A. Delfanti, Open Access and Science Communication. Reflections on the need for a more open communication environment, Jcom 11(02) (2012) E. 